\title{
Problem of obstetrical evacuations of patients coming from maternities outside the coverage zone of the university and hospital center of Treichville (Abidjan-Côte d'Ivoire)
}

\section{Jean Marc Dia ${ }^{1 *}$, Edouard Nguessan', Mohamed Fanny², Mouhideen Oyelade ${ }^{1}$, Gerard Okon ${ }^{1}$, Privat Guie $^{1}$, Simplice Anongba ${ }^{1}$}

\begin{abstract}
${ }^{1}$ Department of Obstetrics and Gynecology, University and Hospital Center of Treichville, Abidjan, Côte d'Ivoire ${ }^{2}$ Department of Obstetrics and Gynecology, University and Hospital Center of Yopougon, Abidjan, Côte d'Ivoire
\end{abstract}

Received: 19 October 2017

Accepted: 17 November 2017

*Correspondence:

Dr. Jean Marc Dia,

E-mail: jmlaminedia@yahoo.fr

Copyright: () the author(s), publisher and licensee Medip Academy. This is an open-access article distributed under the terms of the Creative Commons Attribution Non-Commercial License, which permits unrestricted non-commercial use, distribution, and reproduction in any medium, provided the original work is properly cited.

\begin{abstract}
Background: In developing countries, the organization of obstetrical evacuations is experiencing real problems causing certain preventable maternal and fetal morbidity and mortality. Objective of present study was to describe the sociodemographic characteristics and conditions of transfer of patients from peripheral maternities not dependent on the health coverage zone of the University and Hospital Center of Treichville (called maternity out of zone).

Methods: This is a prospective and descriptive study, conducted at the maternity of the University and Hospital Center of Treichville, from $1^{\text {st }}$ August 2012 to $31^{\text {st }}$ July 2014 about 266 patients evacuated from maternity out of zone. Results: Only $30 \%$ of the patients had properly documented evacuation records. Patients had an average age of 26.9 years, poor follow-up of their pregnancy $(92.1 \%)$, and were generally low socio-economic level: without monthly income $(61.7 \%)$, not attending school $(35.3 \%)$. The majority of evacuations were decided by midwives $(60.9 \%)$ and were done by taxi $(69.5 \%)$. In $71.4 \%$ of the cases, the patients were re-evacuated to our department with the main reason for the unavailability of the operating rooms $(84.3 \%) .46 .6 \%$ of the patients took more than 3 hours to arrive in our department and 35\% arrived in an aggravated condition and sometimes without venous routes. In our department, complications occurred in $27.1 \%$ of the patients, and maternal and fetal death rates were respectively $1.5 \%$ and $21.3 \%$.

Conclusions: This study revealed malfunctions encountered during evacuations: unsafe transportation, transfer card misinformed, long transfer time.
\end{abstract}

Keywords: Indicators, Long transfer time, Obstetrical evacuations, Transfer card misinformed, Unsafe transportation

\section{INTRODUCTION}

In developing countries, the organization of obstetrical evacuations is experiencing real problems causing certain preventable maternal and fetal morbidity and mortality. ${ }^{1}$

To correct some malfunctions and work in network, the Gynecology and Obstetrics department of the Hospital and University Center of Treichville (CHUT) organizes monthly meetings called "common staff" with its collaborators from the peripheral maternity wards of South Abidjan ( Maternities depending all on the health care area of the CHUT).

During these meetings, the management of the patients who have been evacuated from these peripheral maternity 
hospitals is reviewed and recommendations are made on the evacuation conditions of the patients. Very often, maternities outside South Abidjan (whose officials do not participate in the common staff) evacuate patients to the CHUT under inadequate conditions to the recommendations of the common staff.

This study was carried out on patients evacuated by out of zone maternities (located outside South Abidjan) to the CHUT, in order to highlight the difficulties encountered in their way. The objective was to describe the sociodemographic characteristics and the conditions of transfer of the patients evacuated from out of zone maternities.

\section{METHODS}

This study is prospective and descriptive kind, conducted at the maternity CHUT, from $1^{\text {st }}$ August 2012 to $31^{\text {st }}$ July 2014 (24 months) in patients evacuated from out of zone peripheral maternities.

Were included all obstetric-evacuated patients with a properly documented record who arrived alive in the CHUT obstetrics unit. Data were collected from Evacuation sheets, interviews with patients, patient records, delivery records and surgical records.

The parameters analyzed were the socio-demographic characteristics of the patients, and the indicators of evacuations.

The data was entered and analyzed statistically using Epi info, Word and Excel software.

\section{The course of the evacuated patients to the CHUT}

In Abidjan (the capital of Côte d'Ivoire), level II hospitals evacuate their patients to the nearest CHU. Thus, the obstetric services of the 3 University and Hospital Centers (CHU) in Abidjan are the reference centers for maternity units of level II, which are near them. These level II maternities are then referred to as "peripheral maternity" centers of their reference center and "out of zone maternity" compared to other CHU (which are not their natural reference centers).

The CHUT maternity center, located in South Abidjan, is therefore the reference center for peripheral maternity units in the South Abidjan area.

However, in practice, some level II maternity hospitals outside South Abidjan - and which are therefore out of zone maternities in relation to the CHUT- for various reasons, occasionally evacuate patients to the CHUT. In addition, some patients evacuated from out of zone maternity hospitals transit to one of the other CHU before being re-evacuated to the CHUT: this is a re-evacuation. These patients, once at the CHUT, are cared for according to the capacity of the service.

\section{RESULTS}

\section{Epidemiological characteristics}

- Frequency:

During the study period, 12,700 patients were received in the delivery room for an obstetric emergency, of which 7,264 were evacuated (57.2\%). Patients from out of zone maternity units accounted for $12.1 \%$ of all evacuated patients (879 patients). Of these 879 patients, 266 $(30.3 \%)$ had an appropriately completed evacuation record and thus met the inclusion criteria of the study.

\section{Socio demographic characteristics and follow up of pregnancies}

- $\quad$ Age: The average age of the patients was 26.9 years (13 - 43 years)

- Education level: Some patients did not receive any education $(35.3 \%)$, while the others had primary (26.7\%), secondary $(27.8 \%)$ or higher $(10.2 \%)$ education levels.

- Socio-economic level: Patients had no monthly income in $61.7 \%$ of cases, and in $72.9 \%$ the monthly income in the household was less than 152 euros (for a minimum wage of 122 euros in Côte d'Ivoire).

- Pregnancy follow up: $72.1 \%$ of patients had not met all their pregnancy follow-up appointments and $92.1 \%$ had not completed all prenatal check-ups.

Table 1: Distribution of patients according to their age.

\begin{tabular}{|lll|}
\hline Age (years) & Numbers & Frequency $(\%)$ \\
\hline$<18$ & 41 & 15.4 \\
\hline $18-35$ & 155 & 58.3 \\
\hline $35-40$ & 45 & 16.9 \\
\hline$>40$ & 25 & 9.4 \\
\hline Total & 266 & 100.0 \\
\hline
\end{tabular}

\section{Analysis of evacuation indicators}

Origin

Patients came from a variety of out of zone maternity hospitals: 148 patients $(55.7 \%)$ were from maternity hospitals in the zone of the CHU of Cocody, 107 from maternity hospitals in the zone of the CHU of Yopougon $(40.2 \%)$ and 11 patients $(4.1 \%)$ were from centers outside the zone of Abidjan.

\section{Referent agent}

Patients were referred by midwives $(60.9 \%)$, physicians $(21.1 \%)$, and nurse's aides (18\%). 


\section{Evacuation mode}

Patients arrived by taxi in $69.5 \%$ of the cases $(185$ patients), by ambulance in $20.3 \%$ of the cases ( 54 patients), and by private vehicles in $10.2 \%$ of the cases (27 patients).

Table 2: Distribution of patients according to the primary evacuation reasons.

\begin{tabular}{|lll|}
\hline Evacuation reasons & Effective & Percentage \\
\hline Pathology of labor & $(\mathrm{n}=225)$ & 84.6 \\
\hline Dystocia & 96 & 36.1 \\
\hline HTA and its complications & 50 & 18.8 \\
\hline Pre-eclampsia & 44 & 16.5 \\
\hline Eclampsia & 06 & 2.3 \\
\hline Hemorrhage & 21 & 7.9 \\
\hline HRP & 10 & 3.8 \\
\hline PP & 06 & 2.2 \\
\hline Uterine rupture & 05 & 1.9 \\
\hline Fetal Suffering & 38 & 14.3 \\
\hline Other* & 20 & 7.5 \\
\hline Pathology in postpartum & $(\mathrm{n}=41)$ & 15.4 \\
\hline Eclampsia & 15 & 5.6 \\
\hline Postpartum haemorrhage & 21 & 7.9 \\
\hline Fever & 05 & 1.9 \\
\hline Total & 266 & 100.0 \\
\hline
\end{tabular}

Other $*$ : severe anemia ( 8 patients), premature rupture of the membranes (6 patients), cord prolapse beating ( 3 patients), asthma attack ( 2 patients), jaundice febrile (1 patient).

\section{Initial conditioning before evacuation}

The patients were evacuated without venous route in $18.8 \%$ of the cases (50 patients).

\section{Reasons for evacuation to our service}

$71.4 \%$ of the patients were re-evacuated to our department (190 patients) for unavailable operating room in $84.3 \%$ (160 patients).

Table 3: Distribution of patients according to the reasons for evacuation to our service.

\begin{tabular}{|lll|}
\hline Reasons & Effective & $\begin{array}{c}\text { Frequency } \\
(\%)\end{array}$ \\
\hline Bad orientation & & \\
\hline Linked to health worker & 53 & 69.8 \\
\hline Linked to the patient & & \\
\hline Bad experience of other CHU & 15 & 19.7 \\
\hline Preference of CHUT & 8 & 10.5 \\
\hline Total & 76 & 100.0 \\
\hline Re-evacuation* & & \\
\hline Non functional operating room & 92 & 48.5 \\
\hline Busy operating room & 68 & 35.8 \\
\hline Unavailable reanimation room & 20 & 10.5 \\
\hline Unavailable medications (drug) & 10 & 5.2 \\
\hline Total & 190 & 100.0 \\
\hline
\end{tabular}

\section{Duration of the transfer and reasons of the delay}

The transfer lasted less than 1 hour in 21 patients $(7.9 \%)$, between 1 and 2 hours in 40 patients $(15.3 \%)$, between 2 and 3 hours in 81 patients $(30.45 \%)$ and more of 3 hours in 124 patients $(46.62 \%)$.

Reasons for delays (more than one hour) were: reevacuation (49.75\%), traffic jams $(31.7 \%)$, difficulty in obtaining a means of transportation (14.4\%) and distance $(4.41 \%)$.

\section{Evolution}

During the course, the clinical condition remained stable in 173 patients $(65 \%)$, and was worsened in 93 patients $(35 \%)$.

After management in our department, the evolution was simple in 190 patients (71.4\%), with complications in 72 patients $(27.1 \%)$. Mortality was $1.5 \%$ for mothers (4 patients) and $21.3 \%$ for fetuses (48 deaths born).

\section{DISCUSSION}

\section{Epidemiological characteristics}

\section{Frequency}

During the study period, the evacuated patients accounted for the majority of admissions to the CHUT obstetrics department $(57.2 \%)$, with a high rate of patients coming from out of zone maternities (12.1\%). In Africa, evacuation of patients from peripheral maternity wards to reference centers is a common practice reported by several authors. ${ }^{1-3}$ In developed countries such as Canada, on the other hand, evacuations are exceptional, as maternity hospitals generally have a consistent technical equipment which makes it possible to take immediate action. $^{4}$

In addition, it was found that only $30.3 \%$ of patients from out of zone maternities had a properly documented record. The majority of out-of-area evacuees were therefore excluded from the study for an incorrect evacuation record $(69.7 \%)$. In receiving these patients there was therefore no important information about the initial management, which was a serious dysfunction to correct.

\section{Socio demographic characteristics}

Age

The average age of the patients in the study was 26.9 years, close to that found by Diarra (25.1 years) in its series. ${ }^{5}$ In addition, several patients were under 18 years of age $(15.4 \%)$ or over 40 years $(9.4 \%)$. The age of these patients was a risk factor and their delivery should have 
been scheduled in a reference structure to avoid exposing them to an evacuation circuit.

Recognition of risk situations during pregnancy and the anticipation of their management is one of the key points discussed during the common staff with peripheral maternities.

\section{Socio demographic characteristics and follow up of pregnancies}

In the study series, the majority of patients were of low socioeconomic status: without monthly income $(61.7 \%)$, low education level (no education or primary level), and had not correctly followed their pregnancies $(92.1 \%)$. Similar findings have been made in other resourceconstrained African countries. 2,3,6

Targeted free care for pregnant women in Cote d'Ivoire since 2011 has not improved the quality of pregnancy follow up in these low socio-economic patients. This policy did not solve the problems of the first delay (delay in accessing the health center due to the patient or her environment). Therefore, providers need to be made aware of the practice of prenatal consultations, called refocused, which recommend that the socio-economic level of the patients be taken into account during the consultations in order to anticipate certain difficulties that may be linked to their socio-economic status.

\section{Analysis of evacuation indicators}

\section{Origin of patients and referent agent}

In our study, the majority of patients were evacuated by midwives $(60.9 \%)$, and came from out of zone maternities located in Abidjan. These patients should normally be received at the reference $\mathrm{CHU}$ of their origin maternity, but for various reasons they have been received at the CHUT. Similarly, some patients from cities outside Abidjan (4.1\%) were received at the CHUT whereas they should normally be received by the general hospitals in the home towns.

In Côte d'Ivoire, doctors in peripheral health centers do not provide guards in general, and it is important to educate midwives on the appropriateness of the place of transfer of patients.

\section{Evacuation mode}

The majority of patients were not transferred by ambulance (but by taxis and private cars), and this practice is reported in many African publications. ${ }^{1-3,7,8}$ Indeed, several hospitals do not have an ambulance in our low-resource countries, thus delivering patients to nonmedical transport. This type of transport is not secure, and remains exposed to the traps of the frequent traffic congestion in our big cities.

\section{Primary evacuation reason and initial conditioning before evacuation}

The majority of patients were evacuated from their original maternity for labour delivery diseases (84.6\%), involving the life of the mother and the foetus. Moreover, in $71.4 \%$ of the cases, the patients actually arrived in the CHU which had to take care of them, but they were finally re-evacuated to us, mainly due to the unavailability of operating theaters $(84.3 \%)$. Indeed, the obstetric services of the three CHU of Abidjan have the same constraints to operate with only one operating theater for the emergencies. When this operating room is not available, the patients are re-evacuated to other centers, but care is taken to ensure that they are conditioned and to inform the maternity hospitals where they are re-evacuated.

Patients' conditioning before transfer is very important for the prognosis, but we found that several patients arrived in our service without venous route $(18,80 \%)$. This was observed even in some of the re-evacuated patients who arrived without conditioning and without being informed of their imminent arrival.

\section{Duration of the transfer and reasons of the delay}

Almost half of the evacuees (46.62\%) took more than three hours to arrive in our service. This delay is due to reorientation phenomena $(49.75 \%)$, traffic congestion $(32.19 \%)$ and difficulties in obtaining a means of transport (14.14\%).

The re-evacuation delays the care of the patients because they wasted time to go to a first CHU that will not be able to receive them. Since the telephone communication system between the various structures is not well organized, each $\mathrm{CHU}$ should be able to take care of the patients who are evacuated rather than re-evacuating them. We therefore advocate at CHU level the availability of several emergency obstetric operating units, availability of reanimation units, supply of drugs and blood products.

\section{Maternal and neonatal prognosis}

Several patients arrived at the CHUT in an aggravated condition compared to the initial diagnosis (35\%). This is the classic consequences of the 2nd delay (the long transfer time, and non-assistance during the transfer).

Finally, at CHUT, during the management, complications occurred in some patients $(27.1 \%)$, and maternal and fetal death rates were respectively $1.5 \%$ and $21.3 \%$. These deaths could have been avoided if the evacuation system was better coordinated. High death rates among evacuees were also reported in the Cissé series in Senegal and SEPOU in the Central African Republic, which were respectively $6.9 \%$ and $3.6 \% .^{1,3}$ 


\section{CONCLUSION}

This study made it possible to highlight the dysfunctions encountered during evacuation of patients from out-ofarea maternity units to the CHUT obstetrics service: nonmedical transport, incorrect transfer sheet, long transfer time. It is therefore recommended to practice periodic meetings between Level II maternity hospitals and the various reference centers in order to correct certain malfunctions.

Funding: No funding sources Conflict of interest: None declared

Ethical approval: The study was approved by the Institutional Ethics Committee

\section{REFERENCES}

1. Cissé ML, Raad B, Diouf A, Wade F, Moreau JC. Assessment of obstetrical evacuations to the regional hospital of Kolda (Senegal). Med Afr Noire 2010;5701(1):37-43.

2. Ekoundzola JR, Buambo SF, Nkihouabonga G. About 204 parturient referred on the Center Hospital and University of Brazzaville. J SAGO 2003;4(2):15.

3. Sepou A, Goddot M, Ngbale R, Gaunefetc CE, Domande M, Fandemae E, et al. Evolution of frequency and problems related to medical evacuations to the Gynecology and Obstetrics Department of the Bangui Community Hospital. Clin Mothers Child Health 2009;6(1):1007-12.
4. Society of Obstetricians and Gynecologists of Canada. Statement on Wait Times in Obstetrics and Gynecology. J Obstet Gynaecol Can. 2008;30(3):258-70.

5. Diarra AJ, Angbo O, Koffi MN, Koffi MK, Yao TK, Ekra WC. Morbidity and mortality due to the obstetrical transfers in the sanitary district Bouaflé in Côte d'Ivoire. Health Pub. 1999;11(2):193-201.

6. Prual A, Bernis DEL, El Joud OD. Potential role of prenatal care in reducing maternal and perinatal mortality in sub-Saharan Africa. J Gynecol Obstet Biol Reprod. 2002;31(1):90-9.

7. Ouédraogo C, Zoungrana T, Dao B, Dujardin B, Ouédraogo A, Thieba B, et al. Quality caesarean section at the Yalgado Ouagadougou Hospital Center in Ouagadougou. Analysis of the determinants of 478 cases collected in the Obstetrics and Gynecology Department. Med Afr Noire. 2001;48:443-50.

8. Lompo K, Hutin YJF, Traore G, Tall F, Schmid GJB. Morbidity and mortality related to obstetric care evacuations at the Bobo-Dioulasso Hospital, Burkina Faso. Ann Soc Bel Med Trop. 1993;73(2):153-63.

Cite this article as: Dia JM, Nguessan E, Fanny M, Oyelade M, Okon G, Guie P et al. Problem of obstetrical evacuations of patients coming from maternities outside the coverage zone of the university and hospital center of Treichville (Abidjan-Côte d'Ivoire). Int J Reprod Contracept Obstet Gynecol 2018;7:15-9. 